\title{
ОРТОДОНТИЧНИЙ РОЗДІЛ
}

DOI 10.35220/2078-8916-2020-35-1-31-35

УДК 616.314-089.23-073

\section{В. К. Аликулиев}

Азербайджанский медицинский университет Баку Азербайджан

\section{СРАВНИТЕЛЬНЫЙ АНАЛИЗ ЭФФЕКТИВНОСТИ ЛЕЧЕНИЯ ЗУБОЧЕЛЮСТНЫХ АНОМАЛИЙ У ДОПРИЗЫВНИКОВ В СТОМАТОЛОГИЧЕСКИХ КЛИНИКАХ}

Были проанализированы 72 истории болезни лии мужского пола в возрасте от 8 до 17 лет, которые обращались в одну из частных стоматологических клиник г. Баку с различными аномалиями зубочелюстной области, а также 95 историй болезни детей $и$ подростков мужского пола в возрасте от 9 до 17 лет в одной из государственных стоматологических клиник г. Баку. Было установлено, что в частной стоматологической клинике прочент обращений пациентов с зубочелюстными аномалиями в возрасте 8-9 лет составлял 8,3 \%, 10-11 лет - 11,1 \%, 12-13 лет 31,9\%, 14-15 лет - 37,5\%, а 16-17 лет - 11,1\% от общего числа выборки.

Наиболее часто встречаюшимися зубочелюстными аномалиями среди группь пациентов частной стоматологической клиники были аномалии прикуса. Мезиальный тип прикуса был распространен среди 47,2 \% пациентов, особенно часто встречался в возрасте 13,14 и 15 лет - 62,5\%, 80,0\% и 41,7 \% паџиентов соответственно. Дистальный прикус был распространен среди 38,9 \% всей выборки пациентов, наиболее часто встречался в возрасте 12 лет - 53,3\%, 16 лет - $100 \%$ и 17 лет - 60 \% пачиентов. Такие зубочелюстные аномалии, как перекрестный и глубокий прикус занимали 11,1\% и 2,7\% от всей выборки паичентов соответственно.

Выводы. Полученные результаты свидетельствуют о таком важном аспекте здоровья как своевременная диагностика и лечение аномалий зубочелюстной области лич допризывного возраста, которые позволяют значительно увеличить число призывников, годных к прохождению воинской службы. Проведенное исследование показало, что ранняя диагностика заболеваний и использование современных способов их лечения показывает наибольшую эффективность работы стоматологической службы.

Ключевые слова: зубочелюстные аномалии, эффективность лечения, диагностика

\section{В. К. Алікулісв}

Азербайджанський медичний університет Баку Азербайджан

\section{ПОРІВНЯЛЬНИЙ АНАЛІЗ ЕФЕКТИВНОСТІ ЛІКУВАННЯ ЗУБОЩЕЛЕПНИХ АНОМАЛІЙ У ДОПРИЗОВНИКІВ В СТОМАТОЛОГІЧНИХ КЛІНІКАХ}

Було проаналізовано 72 історії хвороби осіб чоловічої статі у віиі від 8 до 17 років, які зверталися в одну з приватних стоматологічних клінік м. Баку з різними аномаліями зубощелепної області, а також 95 історій хвороби дітей і підлітків чоловічої статі у віці від 9 до 17 років в одній з державних стоматологічних клінік м. Баку. Було встановлено, щзо в приватній стоматологічній клініці відсоток звернень пацієнтів із зубощелепними аномаліями у віщуі 8-9 років становив 8,3\%, 10-11 років - 11,1\%, 12-13 років - 31,9\%, 14-15 років - 37,5 \%, а 16-17 років - 11,1\% від загального числа вибірки.

Найбільи часто зустрічаються зубощелепні аномалії серед групи пацієнтів приватної стоматологічної клініки були аномалії прикусу. Мезіальний тип прикусу був поширений серед 47,2\% пацієнтів, особливо часто зустрічався у віиі 13,14 і 15 років - 62,5\%, 80,0\% $i$ 41,7\% пацієнтів відповідно. Дистальний прикус був поширений серед 38,9 \% всієї вибірки пацієнтів, найбільш часто зустрічався у віці 12 років - 53, 3 \%, 16 років - $100 \%$ і 17 років - $60 \%$ паціснтів. Такі зубощелепні аномалії, як перехресний $i$ глибокий прикус займали 11,1\% і 2,7 \% від усієї вибірки пащуієнтів відповідно.

Висновки. Отримані результати свідчать про такий важливий аспект здоров'я як своєчасна діагностика $i$ лікування аномалій зубошелепної області осіб допризовного віку, які дозволяють значно збільшити число призовників, придатних до проходження військовоі служби. Проведене дослідження показало, щчо рання діагностика захворювань $i$ використання сучасних способів їх лікування показує найбільшу ефективність роботи стоматологічної служби.

Ключові слова: зубощелепні аномалї, ефективність лікування, діагностика

\section{K. Aliguliev}

Azerbaijan medical University, Baku, Azerbaijan

\section{COMPARATIVE ANALYSIS \\ OF THE EFFECTIVENESS OF TREATMENT OF DENTAL ANOMALIES IN PRE-CONSCRIPTS IN DENTAL CLINICS}

We analyzed 72 medical histories of male patients aged 8 to 17 years, who applied to one of the private dental clinics in Baku with various anomalies of the dental region, as well as 95 medical histories of male children and 
adolescents aged 9 to 17 years in one of the state dental clinics in Baku. It was found that in a private dental clin$i c$, the percentage of patients with dental anomalies aged 8-9 years was $8.3 \%, 10-11$ years- $11.1 \%, 12-13$ years$31.9 \%, 14-15$ years $-37.5 \%$, and $16-17$ years $-11.1 \%$ of the total sample.

The most common dental anomalies among the group of patients at a private dental clinic were malocclusions. Mesial bite type was common among $47.2 \%$ of patients, especially common at the age of 13.14 and 15 years $62.5 \%, 80.0 \%$ and $41.7 \%$ of patients, respectively. Distal occlusion was common among $38.9 \%$ of the entire sample of patients, most common at the age of 12 years$53.3 \%$, 16 years $-100 \%$ and 17 years $-60 \%$ of patients. Dental anomalies such as cross and deep bite occupied $11.1 \%$ and $2.7 \%$ of the total sample of patients, respectively.

Conclusions. The results obtained indicate such an important aspect of health as timely diagnosis and treatment of anomalies of the dental region of persons of preconscription age, which can significantly increase the number of conscripts who are fit for military service. The study showed that early diagnosis of diseases and the use of modern methods of their treatment shows the greatest efficiency of the dental service.

Key words: dentofacial anomalies, the effectiveness of treatment, diagnosis.

Введение. Укрепление здоровья подростков и юношей является одной из приоритетных задач национальной политики в области охраны здоровья населения, решение которой позволит изменить неблагоприятные тенденции, улучшить демографию, повысить качество их жизни и обеспечит возможность полноценного комплектования Вооруженных сил [1].

Изучение встречаемости стоматологических аномалий у молодых людей в современных условиях экономического развития и системы здравоохранения позволяет оценить эффективность и качество оказания им стоматологической помощи [2]. В последние годы значительно увеличилось количество лиц с разными формами поражения зубочелюстной системы [3]. В то же время, использование замещающих технологий взамен профилактического подхода в стоматологии приводит к увеличению потребности подростков и юношей в различных видах стоматологической помощи, в том числе и ортодонтической, в перспективе нескольких лет [4]. Для планирования работы военно-врачебных комиссий во время призыва необходимы актуальные статистические данные по анализу аномалий челюстно-лицевой области [2]. В связи с этим, юноши в период подготовки к военной службе нуждаются в своевременном проведении медицинских осмотров и диспансерном наблюдении, а также проведении комплекса лечебно-оздоровительных и профи- лактических мероприятий, направленных на улучшение показателей их здоровья [5]. Военноврачебным комиссиям военных комиссариатов рекомендуется налаживать более тесное взаимодействие с местными органами здравоохранения, сообща повышать контроль за проведением лечебно-оздоровительных мероприятий среди молодежи допризывного и призывного возрастов [6]. Организация медицинского обеспечения призывников требует постоянного взаимодействия учреждений здравоохранения и военных комиссариатов на муниципальном и региональном уровнях [5], что подчеркивает актуальность данного исследования.

Цель исследования. Сравнительный анализ эффективности работы стоматологических клиник частной и государственной форм собственности с учетом возраста обращения допризывников.

Материалы и методы. Были проанализированы 72 истории болезни лиц мужского пола в возрасте от 8 до 17 лет, которые обращались в одну из частных стоматологических клиник г. Баку с различными аномалиями зубочелюстной области, а также 95 историй болезни детей и подростков мужского пола в возрасте от 9 до 17 лет в одной из государственных стоматологических клиник г. Баку.

Структура выборки и типы аномалий проанализированных историй болезни пациентов частной клиники представлены в табл. 1. Было установлено, что в частной стоматологической клинике процент обращений пациентов с зубочелюстными аномалиями в возрасте 8-9 лет составлял 8,3\%, 10-11 лет - 11,1\%, 12-13 лет $31,9 \%, 14-15$ лет $-37,5 \%$, а $16-17$ лет $-11,1 \%$ от общего числа выборки.

Наиболее часто встречающимися зубочелюстными аномалиями среди данной группы пациентов частной стоматологической клиники были аномалии прикуса. Мезиальный тип прикуса был распространен среди 47,2 \% пациентов, особенно часто встречался в возрасте 13,14 и 15 лет - 62,5 $\%, 80,0 \%$ и 41,7\% пациентов соответственно. Дистальный прикус был распространен среди 38,9 \% всей выборки пациентов, наиболее часто встречался в возрасте 12 лет - 53,3\%, 16 лет $100 \%$ и 17 лет - 60 \% пациентов. Такие зубочелюстные аномалии, как перекрестный и глубокий прикус занимали $11,1 \%$ и $2,7 \%$ от всей выборки пациентов соответственно.

Результаты проведенного лечения показали высокую общую среднюю эффективность - 95,8 $\%$ и $100 \%$ результат среди пациентов в возрасте 8-11 лет, 13 и 16 лет. Отдельно стоит отметить снижение эффективности лечения с увеличением 
возраста пациентов (например, в 17 лет эффективность снижалась до $80 \%)$.

Структура выборки и типы аномалий проанализированных историй болезни пациентов го- сударственной стоматологической клиники представлены на табл. 2.

Таблица 1

\section{Результаты анализа историй болезни пациентов частной стоматологической клиники} г. Баку и эффективности их лечения

\begin{tabular}{|c|c|c|c|c|c|c|}
\hline \multirow{2}{*}{$\begin{array}{c}\text { Возраст обраще- } \\
\text { ния в клинику, } \\
\text { полных лет }\end{array}$} & \multirow{2}{*}{$\begin{array}{l}\text { Мальчики, } \\
\text { число }\end{array}$} & \multicolumn{4}{|c|}{ Тип зубочелюстной аномалии } & \multirow{2}{*}{$\begin{array}{c}\text { Эффективность } \\
\text { лечения,\% }\end{array}$} \\
\hline & & $\begin{array}{c}\text { дистальный } \\
\text { прикус }\end{array}$ & $\begin{array}{c}\text { мезиальный } \\
\text { прикус }\end{array}$ & $\begin{array}{c}\text { перекрестный } \\
\text { прикус }\end{array}$ & $\begin{array}{c}\text { глубокий } \\
\text { прикус }\end{array}$ & \\
\hline 8 & 3 & 0 & 0 & 3 & 0 & 100 \\
\hline 9 & 3 & 3 & 0 & 0 & 0 & 100 \\
\hline 10 & 5 & 0 & 5 & 0 & 0 & 100 \\
\hline 11 & 3 & 0 & 3 & 0 & 0 & 100 \\
\hline 12 & 15 & 8 & 2 & 3 & 2 & 93,3 \\
\hline 13 & 8 & 3 & 5 & 0 & 0 & 100 \\
\hline 14 & 15 & 3 & 12 & 0 & 0 & 93,3 \\
\hline 15 & 12 & 5 & 5 & 2 & 0 & 91,7 \\
\hline 16 & 3 & 3 & 0 & 0 & 0 & 100 \\
\hline 17 & 5 & 3 & 2 & 0 & 0 & 80 \\
\hline Всего & 72 & 28 & 34 & 8 & 2 & 95,8 \\
\hline
\end{tabular}

Таблица 2

Результаты анализа историй болезни пациентов государственной стоматологической клиники г.Баку и эффективности их лечения

\begin{tabular}{|c|c|c|c|c|c|c|c|c|c|}
\hline $\begin{array}{c}\text { Возраст } \\
\text { обращения } \\
\text { в клинику, } \\
\text { полных лет }\end{array}$ & $\begin{array}{c}\text { Маль } \\
\text { чики, }\end{array}$ & $\begin{array}{c}\text { Дисталь } \\
\text { ный } \\
\text { прикус }\end{array}$ & $\begin{array}{c}\text { Мези- } \\
\text { альый } \\
\text { прикус }\end{array}$ & $\begin{array}{c}\text { Откры- } \\
\text { тый } \\
\text { прикус }\end{array}$ & $\begin{array}{c}\text { Нижняя } \\
\text { макр- } \\
\text { гнатия }\end{array}$ & $\begin{array}{c}\text { Верхняя } \\
\text { макро- } \\
\text { гнаияя }\end{array}$ & $\begin{array}{c}\text { Нижняя } \\
\text { микро- } \\
\text { гнатия }\end{array}$ & $\begin{array}{c}\text { Верхняя } \\
\text { микр- } \\
\text { гнатия }\end{array}$ & $\begin{array}{c}\text { Эффектив- } \\
\text { ность лече- } \\
\text { ния, \% }\end{array}$ \\
\hline 9 & 3 & 0 & 0 & 0 & 3 & 0 & 0 & 0 & 100 \\
\hline 10 & 3 & 0 & 0 & 0 & 3 & 0 & 0 & 0 & 100 \\
\hline 11 & 7 & 0 & 0 & 3 & 4 & 0 & 0 & 0 & 28,6 \\
\hline 12 & 8 & 0 & 2 & 0 & 0 & 0 & 0 & 6 & 25,0 \\
\hline 13 & 4 & 0 & 0 & 2 & 0 & 2 & 0 & 0 & 100 \\
\hline 14 & 17 & 0 & 0 & 9 & 6 & 0 & 0 & 2 & 52,9 \\
\hline 15 & 16 & 2 & 0 & 2 & 5 & 0 & 0 & 7 & 68,8 \\
\hline 16 & 19 & 3 & 4 & 5 & 3 & 0 & 0 & 4 & 84,2 \\
\hline 17 & 18 & 2 & 0 & 3 & 7 & 0 & 2 & 4 & 66,7 \\
\hline Всего & $\mathbf{9 5}$ & $\mathbf{7}$ & $\mathbf{6}$ & $\mathbf{2 4}$ & $\mathbf{3 1}$ & $\mathbf{2}$ & $\mathbf{2}$ & $\mathbf{2 3}$ & $\mathbf{7 2 , 0}$ \\
\hline
\end{tabular}

В результате проведенного анализа было установлено, что в государственной стоматологической клинике процент обращений пациентов с зубочелюстными аномалиями в возрасте 9 лет составлял 3,2 \%, 10-11 лет - 10,5\%, 12-13 лет $12,6 \%, 14-15$ лет - 34,7 \%, а 16-17 лет - 38,9\% от общего числа выборки. В сравнении с результатами анализа истории болезни пациентов частной клиники, в государственной клинике было зафиксировано значительно большее число обращений пациентов в возрасте 16-17 лет (на 27,8
\% больше), а также меньший процент пациентов в возрасте 12-13 лет (на 19,3\%).

В отличие от частной стоматологической клиники, кроме открытого прикуса, в государственной стоматологической клинике, наиболее часто встречающимися зубочелюстными аномалиями были нижняя макрогнатия, открытый прикус и верхняя микрогнатия.

Нижняя макрогнатия была зафиксирована у $32,6 \%$ пациентов, особенно часто в возрасте 9 лет $(100 \%), 10(100 \%), 11$ (57 \%), 14-15 лет (33,3 
\%) и 16-17 лет (27,0 \%). Открытый прикус встречался у 25,3\% пациентов, особенно часто в 14 лет $(52,9$ \%). Верхняя микрогнатия была зафиксирована у $24,2 \%$ пациентов, особенно часто в возрасте 12 и 15 лет - 18,1 \% и 43,8 \% соответственно. Такие зубочелюстные аномалии, как дистальный и мезиальный прикусы, верхняя макрогнатия и нижняя микрогнатия занимали меньшую долю среди всей выборки пациентов - 7,4 $\%, 6,3 \%, 2,1 \%$ и 2,1\% соответственно.

Результаты исследований и их обсуждение. Результаты проведенного лечения показали более низкую среднюю эффективность лечения в государственной клинике в сравнении с частной стоматологической клиникой - на 23,83 \%, показав $100 \%$ результат только среди пациентов в возрасте 9-10 и 13 лет. Отдельно стоит отметить снижение эффективности лечения в возрасте 11,12 и 14,15 лет (на 71,4 \%, 68,3 \%, 40,4 \% и $22,9 \%$ ниже в сравнении с результатами частной клиники). Также, было зафиксировано более успешное лечение пациентов в возрасте 16 лет в частной стоматологической клинике - на 15,8 \%, а в возрасте 17 лет - на 13,3\%.

Важным моментом при оценке эффективности работы частной и государственной стоматологических клиник является сравнение успешности лечения одного и того же типа зубочелюстных аномалий. Так, среди обеих групп пациентов были зафиксированы случаи дистального и мезиального прикуса, однако следует учитывать специфичность обоих исследованных нами выборок и отсутствие среди отдельных возрастных категорий пациентов случаев данных аномалий. В результате проведенного анализа эффективность лечения дистального прикуса в частной клинике составляла 96,4 \%, а в государственной - 57,1\%, что было ниже на 39,3\%. Также, стоит отметить, что $100 \%$ успешное лечение дистального прикуса в частной клинике наблюдалось в возрастных группах 9-16 лет, а среди пациентов в возрасте 17 лет составляло 66,6 \%. В то же время, в государственную клинику обращались с данной аномалией только пациенты в возрасте 15-17 лет, эффективность их лечения составляла $100 \%$ только в возрасте 15 лет, а в возрасте 16 и 17 лет составляла $66,6 \%$ и 50 \% соответственно.

Успешность лечения мезиального прикуса в частной клинике составляла 91,2 \%, в то время как в государственной клинике - 66,6 \%, что было ниже на 24,6 \%. Стоит отметить, что в частной клинике была зафиксирована $100 \%$ успешность лечения мезиального прикуса в возрасте 10-12 и 17 лет, а в возрасте 13 лет - 80\%, 14 $83,3 \%, 15$ - $80 \%$. Успешность лечения данной аномалии в государственной клинике составляла $50 \%$ в возрасте 12 лет и $75 \%$ в возрасте 16 лет.
В остальных возрастных категориях пациентов с данной аномалией зафиксировано не было.

В ходе работы была оценена эффективность лечения и других типов аномалий. Так, в частной стоматологической клинике эффективность лечения перекрестного прикуса составляла 87,5 \%, включая $100 \%$ успешное лечение в возрастной категории 8 и 15 лет и 66,6 \% в возрастной категории 12 лет. Лечение глубокого прикуса было успешно в $100 \%$ случаев.

В государственной стоматологической клинике лечение открытого прикуса показало эффективность 62,5 \%. Наибольшая эффективность была установлена среди возрастной категории 13 лет (100\%),16 лет (80\%) и 17 лет (66,6\%). В то же время среди пациентов 11 лет она составляла $33,3 \%, 14$ лет - 55,5\% и среди 15 лет - 50\%.

Лечение нижней макрогнатии показало эффективность $71 \%$. Наибольший результат был достигнут в возрастной категории 15 и 17 лет (80 \% и 71,4 \%), более низкий результат был зафиксирован в возрастных категориях 11 и 14 лет (25 \% и 50 \%). Эффективность лечения верхней макрогнатии составляла $100 \%$, однако следует учесть незначительный размер выборки пациентов с данной аномалией $(n=2)$. Данное утверждение справедливо и для оценки эффективности лечения в группе с нижней микрогнатией (50\%, $\mathrm{n}=2$ ).

Проведенный анализ показал, что лечение верхней микрогнатии было эффективно на 56,5 \%. Наиболее высокие результаты были достигнуты в возрастной категории 15 и 17 лет (57,1\% и $75 \%$ ), в то время как в категориях 12 и 14 лет успешность лечения данной аномалии составляла $16,7 \%$ и $50 \%$.

Таким образом, результаты проведенного нами анализа историй болезни лиц детского и подросткового возраста, которые проходили лечение в частной и государственной стоматологических клиниках, показали, что в государственной клинике было зафиксировано значительно большее число обращений пациентов в возрасте 16-17 лет (на 27,8 \% больше), а также меньший процент пациентов в возрасте 12-13 лет (на 19,3 \%) в сравнении с данными частной клиники. Кроме того, анализ итогов проведенного лечения показал на 23,83 \% более низкую среднюю эффективность в государственной клинике $(72,0 \%)$ в сравнении с частной (95,8 \%). Специфика изученных выборок позволила сравнить эффективность работы двух клиник по лечению двух типов аномалий. Так, эффективность лечения дистального прикуса в частной клинике составляла $96,4 \%$, а в государственной - 57,1 \%, что было ниже на 39,3 \%, а успешность лечения мезиального прикуса в частной клинике $(91,2$ \%) была 
выше на 24,6 \%, в сравнении с государственной клиникой $(66,6$ \%). Было установлено, что с увеличением возраста обращения эффективность лечения зубочелюстных аномалий снижается, особенно в условиях государственной стоматологической клиники.

В результате проведенных исследований мы пришли к выводу о существенных различиях в эффективности работы стоматологических служб в городе Баку и регионах Азербайджана. Учитывая частоту распространенности аномалий зубочелюстной области призывников в регионах, нами была выдвинуто предположение о недостаточной эффективности работы стоматологической службы с лицами детского и допризывного подросткового возраста, которая должна базироваться на своевременной диагностике и лечений зубочелюстных аномалий для увеличения числа здоровых призывников в будущем.

Bыводы. Полученные результаты свидетельствуют о таком важном аспекте здоровья как своевременная диагностика и лечение аномалий зубочелюстной области лиц допризывного возраста, которые позволяют значительно увеличить число призывников, годных к прохождению воинской службы. Проведенное исследование показало, что ранняя диагностика заболеваний и использование современных способов их лечения показывает наибольшую эффективность работы стоматологической службы.

\section{Список литературы}

1. Солдаткина А.С. Характеристика стоматологического здоровья молодого населения России. Актуальные проблемы стоматологии Арктического региона, современные тенденции и перспективы диагностики, лечения и профилактики стоматологических заболеваний / А.С. Солдаткина, А.А. Сериков - Архангельск: Изд-во СГМУ, 2015. - С. 85-87.

2. Иорданишвили А. К. Стоматологические заболевания у лиц призывного возраста / А. К. Иорданишвили, А. С. Солдаткина, А. А. Сериков. // Вестник Российской военно-медицинской академии. - 2015. - №. 4. - С. 106-108.

3. Иорданишвили А. К. Проблемные вопросы медицинского освидетельствования молодёжи призывного возраста в связи со стоматологической патологией / А. К. Иорданишвили, Л. Н. Солдатова // Кубанский научный медицинский вестник. - 2016. - №. 4. - С.53-56.

4. Иорданишвили А. К. Особенности обследования и медицинского освидетельствования граждан при постановке на воинский учет, призывающихся на военную службу и поступающих в военно-учебные учреждения, при наличии у них зубочелюстных аномалий / А. К. Иорданишвили, Л. Н. Солдатова Курский научно-практический вестник «Человек и его здоровье». - 2016. - №. 3. - С12-16.

5. Кузьмин С. А. Анализ показателей здоровья допризывной и призывной молодежи Оренбургской области / С. А. Кузьмин, В. В. Солодовников, Э. М. Вахитов, А. П. Галин // Известия Самарского научного центра Российской академии наук. - 2015. - Т. 17. №. 5-2. - С.490-494.

6. Шашмурина В. Р. Значение патологии зубочелюстной системы в медицинском освидетельствовании граж- дан при постановке на воинский учет и призыве на военную службу / В. Р. Шашмурина, Л. В. Кузьмина, О. Л. Мишутина, А. Б. Шашмурина // Вестник Смоленской государственной медицинской академии. - 2018. - Т. 17. - №. 3. - С.187192.

\section{REFERENCES}

1. Soldatkina A.S., Serikov A.A. Kharakteristika stomatologicheskogo zdorov'ya molodogo naseleniya Rossii. Aktual'nye problemy stomatologii Arkticheskogo regiona, sovremennye tendentsii $i$ perspektivy diagnostiki, lecheniya $i$ profilaktiki stomatologicheskikh zabolevaniy [Characteristics of dental health of the young population of Russia. Current problems of dentistry in the Arctic region, current trends and prospects for the diagnosis, treatment and prevention of dental diseases] Arkhangel'sk: Izd-vo SGMU; 2015:85-87.

2. Iordanishvili A. K., Soldatkina A. S., Serikov A. A. Dental diseases in persons of military age. Vestnik Rossiyskoy voenno-meditsinskoy akademii. 2015;4:106-108.

3. Iordanishvili A. K., Soldatova L. N. Problematic issues of medical examination of young people of military age in connection with dental pathology. Kubanskiy nauchnyy meditsinskiy vestnik. 2016; 4:53-56.

4. Iordanishvili A. K., Soldatova L. N. Features of examination and medical examination of citizens when registering for military service, who are called up for military service and entering military educational institutions, if they have dental anomalies. Kurskiy nauchno-prakticheskiy vestnik «Chelovek $i$ ego zdorov'e». 2016; 3:12-16.

5. Kuz'min S. A., Solodovnikov V. V., Vakhitov E. M., Galin, A. P. Analysis of health indicators of pre-conscription and conscription youth of the Orenburg region.Izvestiya Samarskogo nauchnogo tsentra Rossiyskoy akademii nauk. 2015;5-2(17):490-494.

6. Shashmurina V. R., Kuz'mina, L. V., Mishutina, O. L., Shashmurina A. B. The significance of dental pathology in the medical examination of citizens during registration for military service and conscription. Vestnik Smolenskoy gosudarstvennoy meditsinskoy akademii. 2018;3(17):187-192.

Поступила 17.01.2020

DOI 10.35220/2078-8916-2020-35-1-35-40

УДК 616.314-089.23:577.121

\section{А.Э. Деньга, к. мед. н.}

Государственное учреждение «Институт стоматологии и челюстно-лицевой хирургии

Национальной академии медицинских наук Украины»

\section{БИОФИЗИЧЕСКИЕ ПОКАЗАТЕЛИ \\ ТКАНЕЙ ПАРОДОНТА И ЖИРОВОЙ МАССЫ ТЕЛА ПАЦИЕНТОВ \\ С МЕТАБОЛИЧЕСКИМ СИНДРОМОМ \\ В ПРОЦЕССЕ КОМПЛЕКСНОГО ОРТОДОНТИЧЕСКОГО ЛЕЧЕНИЯ}

Показано, что у паџиентов, направленных на ортодонтическое лечение, с метаболическим синдромом и хроническим генерализованным пародонтитом 